\title{
Designing a Test Fixture with DFSS Methodology
}

\author{
Charles G. Kibbe, Jim Lee, and Kanjicai Dong \\ Systems Engineering Program, College of Engineering, University of Louisiana at Lafayette, Lafayette, LA, USA \\ Correspondence should be addressed to Jim Lee; jlee@louisiana.edu
}

Received 31 July 2016; Revised 28 November 2016; Accepted 30 November 2016

Academic Editor: Godfrey C. Onwubolu

Copyright (c) 2016 Charles G. Kibbe et al. This is an open access article distributed under the Creative Commons Attribution License, which permits unrestricted use, distribution, and reproduction in any medium, provided the original work is properly cited.

\begin{abstract}
This paper addresses the application of Design for Six Sigma (DFSS) methodology to the design of a marine riser joint hydraulic line test fixture. The original test fixture was evaluated using Value Steam Mapping (VSM) and appropriate Lean design tools such as 3D Modeling and Finite Element Analysis (FEA). A new test fixture was developed which resulted in improving the process cycle efficiency for the test from $25 \%$ to $50 \%$ percent, leading to a $50 \%$ reduction in test cost. Handling of the new test fixture is greatly improved as compared to the original fixture.
\end{abstract}

\section{Introduction}

This paper explores the use of Lean Six Sigma in the design process. Specifically, it focuses on the use of Design for Six Sigma (DFSS) concept and how this approach and Lean tools can be applied to the design of a marine riser joint hydraulic line test fixture. A marine riser is a conduit that provides a connection between a subsea oil well and the drilling vessel on the water surface. It serves as a conduit to house the drill string and to allow transport of the drilling or completion fluids back to the surface. It is essentially an extension of the subterranean well bore, taking the well bore's place between the sea floor and the drilling vessel on the surface.

This marine riser is assembled on a temporary basis to be used during drilling and well completion operations and is then disassembled when drilling operations are complete. These marine risers can extend many hundreds of feet into the water. Due to the temporary nature of these marine risers and the fact that they must accommodate varying water depths, they are built as assemblies of modular segments called "joints." This allows the total riser length to be adjusted by adding or subtracting joints as needed. Each joint of marine riser is comprised of a large central pipe that serves as the main conduit for drilling operations. Flanking this large pipe is a number of smaller pipes, called lines. These outer lines allow operation of equipment located at the sea floor, among other tasks. One of these tasks is to supply hydraulic power to the equipment, such as Blow Out Preventers (BOPs), located on the sea floor.

The DFSS process is composed of five steps known as DMADV. This acronym stands for Define, Measure, Analyze, Design, and Verify. Using this process, we will define the objectives of the project and the problem to be solved, measure and identify the issues that are critical to quality, analyze the data obtained, develop possible solutions, choose the best solution, complete the design work using appropriate Lean design tools, and then verify the solution against the original project objectives. We believe that the techniques shown can be utilized for other similar design tasks.

\section{Review of Lean Six Sigma Design Tools}

The concept of Lean Six Sigma is traditionally thought of as applicable to the operation of a manufacturing facility or operation. Womack et al. [1] described in detail how these techniques were used to great effect in the automobile manufacturing industry. Initially Six Sigma was viewed as a method of reducing waste and then was viewed as a way to enhance quality while reducing cost and delivery times.

Eventually the focus began to move towards value enhancement and new techniques such as "Lean" were introduced. Browning [2] stated that "Lean is not minimizing cost, cycle time, or waste, Lean is maximizing value." Lean 
can now be thought of as an approach to create value for the customer by reducing or eliminating wasteful activities. From this perspective, Lean and Six Sigma techniques can be applied beyond the confines of manufacturing to other areas such as product design.

Näslund [3] found the more recent concepts of Lean and Six Sigma have mainly replaced total quality management (TQM) and just-in-time (JIT). Lean production, total quality management, Six Sigma, Production processes, Paper type General review, and Introduction Lean have been marketed as a new organizational change and improvement method, particularly as a cost reduction mechanism. Lean strives to make Lean Six Sigma and Lean Sigma organizations more competitive in the market by increasing efficiency; decreasing costs incurred due to nonvalue adding steps and inefficiencies in the processes; by reducing cycle times, therefor profits for the organization increased.

Pepper and Spedding [4] stated that to achieve a truly Lean operation, Lean Six Sigma needs to be methodically evolved before other tools. The evolution of Lean Six Sigma should be used as an enabler for strategic development rather than a tool for downsizing. Lean philosophies were applied to large manufacturing operations in high-volume, low-variety facilities. The phrase "Lean Six Sigma" is used to describe the integration of Lean and Six Sigma philosophies. Specifically, in the case of fusing Lean and Six Sigma, the two approaches have often been implemented in isolation. Also creating Lean and Six Sigma subcultures to emerge within the organization can cause a conflict of interest and a drain on resources. Competitive advantage of Lean Six Sigma and Lean Six Sigma techniques are also used to consider and improve the organization on an operational level, reducing complexity and interactions within the system, through the targeted removal of nonvalue adding activities.

Haggerty et al. [5] showed how value stream mapping can be applied to the product development cycle and showed how engineering plays a critical role in creating value in an enterprise. Kihn [6] reported greatly improved product development cycle times by applying Lean thinking to engineering. He also stated that visual planning techniques can help make Lean thinking more intuitive by making waste visible. Kennedy [7] described how Toyota engineers use Lean techniques to operate at amazing productivity levels. Schmidt and Schipper [8] described in detail how Lean techniques are applied to the design of office furniture. It is clear that these techniques can be applied with great success to activities outside of the traditional manufacturing environment.

Chugani et al. [9] research on Lean Six Sigma appeared under the searches of "Lean" as well as those of "Six Sigma." They studied ten companies and deduced that despite the vast amount of literature that suggests that Lean leads to sustainable supply chains, Lean may not be a factor that promotes sustainability. While their study points out the difficulty in applying Lean appropriately, it is premature to suggest that Lean is not a factor that contributes to sustainability. With global warming, pollution, and Lean's impact, one may wonder how a quality and operations improvement philosophy like Lean can contribute to decrease in pollution and thereby combat global warming.

McManus et al. [10] described some typical Lean engineering tools that can be used to streamline and improve the design process. These include Design for Manufacturing and Assembly (DFMA), Solid Model Based Design, Variability Reduction and Dimensional Management, and product simulation with Finite Element Analysis (FEA). Several of these have direct benefit to the problem addressed in this research. DFMA can be applied to reduce the complexity level and improve the ease of use of the riser hydraulic line test fixture. Keeping handling in mind throughout the design process can contribute to a final design that will meet one of the key design goals of a faster and safer test process.

Solid Model Based Design or 3D modeling can be used to allow the customer to more easily visualize the replacement test fixture as it is being designed. This approach has the potential to greatly reduce the design cycle time and can lead to a better design through improved design reviews. Additionally, modeling the improved test fixture in 3D can identify fit/clearance/interference issues before the parts are manufactured reducing the time and cost associated with scrap and rework. During the manufacturing process, these 3D models can be used to program computer aided manufacturing (CAM) machines to verify machining programs and during the product quality control process.

Variability Reduction/Dimensional Management can be addressed by completing tolerance accumulation analysis on the key fit areas of the tool. Combining accurately calculated tolerances with accurately applied Geometric Dimensioning and Tolerancing (GD\&T) feature control information will allow for more effective communication of design intent to the machine shop. Mehta [11] described how effective GD\&T application can contribute to improved designs.

Another design tool addressed by McManus et al. [10] was product simulation. Powerful tools such as ANSYS Finite Element Analysis (FEA) can be utilized to simulate the working conditions seen by the test fixture. By accurately testing the new design before manufacturing, design issues can be identified early and corrected before manufacturing. Johnston [12] showed how FEA in conjunction with 3D modeling can be used for product validation and system optimization as well as verifying physical experimentation.

Mason et al. [13] concluded that Lean and Six Sigma methodologies have the potential to produce clinically significant improvements for surgical patients. However, there is a need to conduct high-quality studies with low risk of systematic bias in order to further understand their role. Due to the inability to perform meta-analysis, single effect sizes of interventions could not be estimated; therefore, while collating studies within common aims, the intervention effects had to be considered on an individual basis. The concept of imprecision is that although an improvement may be statistically significant, there may be significant clinical implications for the point at which the true effect lies within the $95 \%$ confidence interval. Despite the studies presented here most often focusing on improving clinical measures and the methodological rigor of using Six Sigma and Lean, it is noteworthy that $48 \%$ of the studies did not present $95 \%$ 
TABLE 1: Lean design tools.

\begin{tabular}{lr}
\hline Tool & Application \\
\hline Value stream mapping & Identifying process steps and opportunities for improvement \\
DFMA & Reduction of design complexity and increase of manufacturability \\
3D modeling & Ease of product visualization, improved design reviews, and reduced error due to missed interferences \\
GD\&T & More effective communication of design intent and reduction of manufacturing errors \\
FEA & Allowing virtual testing and optimization of design before costly components are manufactured \\
\hline
\end{tabular}

confidence interval and a further $26 \%$ provided no evidence of statistical analysis at all.

Douglas et al. [14] stated Lean Six Sigma describes the integration of the Lean philosophy and associated tools and techniques with the Six Sigma philosophy and its associated tools and techniques. Lean Six Sigma combines the waste elimination tools and techniques of Lean with the variation reduction tools and techniques of Six Sigma. This pilot study reports on the implementation of Lean Six Sigma in East African service and manufacturing organizations. The aim is to determine the critical success factors for implementation of such a strategy as well as any barriers. Also, because Lean Six Sigma is dependent upon a vast array of tools and techniques for its success, the aim was to determine the knowledge, use, and usefulness of such tools among improvement practitioners. Results indicate that the most useful tools are most of the original 7 tools of quality improvement proposed by Ishikawa over 50 years ago and the most important factor for successful implementation of Lean Six Sigma is management involvement and participation. participation. A case study of using Six Sigma procedure is shown in Mishra [15].

Review of the literature indicates how Six Sigma techniques can be used to guide improved design processes. Also a number of Lean engineering tools were identified that can be used to streamline the engineering process while also producing superior designs. Table 1 summarizes some Lean tools found in the literature that can be used to assist with the DFSS process.

\section{DFSS and DMADV Process}

This paper addresses the real world application of these techniques and tools to the design of a marine riser joint hydraulic line test fixture. However, the techniques shown can be utilized for other similar design tasks. In order to apply DFSS to the design of an improved test fixture, a flowchart was constructed defining the process steps. The DAMDV structure was utilized and objectives for each step were defined. Specific tools will be utilized to address the issues specific to this design problem; however, other tools can be utilized within the same framework to apply the DFSS approach to other design problems. Figure 1 shows this flowchart, defining the major steps in the design process. Each step is discussed in the following section.

3.1. Define. Due to the sensitive nature of drilling operations in the ocean, the damaging effects of salt water, drilling

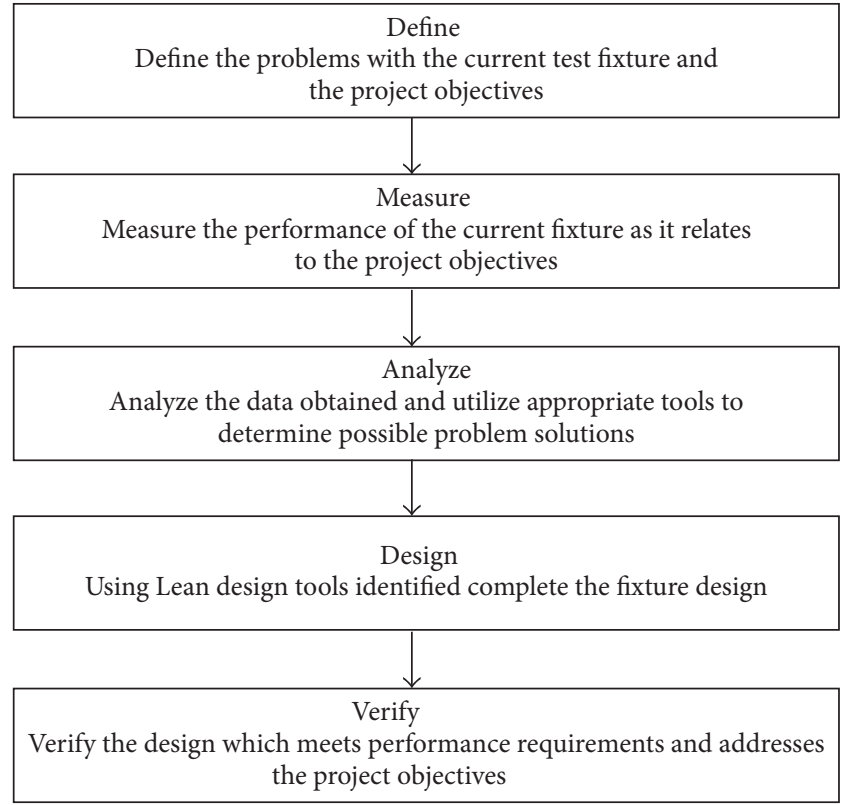

FIGURE 1: DFSS methodology flowchart.

fluids, and well bore fluids, and the large pressures involved, regular testing is performed on marine riser joints before they are deployed on a drilling job. Part of this testing involves measuring the pressure integrity of the smaller outer lines attached to the marine riser joints. This testing is performed on each individual joint. As such, test fixtures are required for each end of the smaller outer pipes to create a closed environment which will allow the lines to be filled with water and then pressurized.

In order to perform these tests on the small outer riser lines, a relatively large and complicated test fixture is attached to each end of the outer line of one joint of the riser. Once the test fixture is assembled, the line can be filled with water and pressured up to test pressure. This test pressure is then held for a set amount of time. Once the pressure test is complete, the pressure is removed and the test fixture is disassembled. The fixture is then moved to the next line on the joint of riser, and the process continues.

Using the existing riser design, the time required to assemble and disassemble the test fixture is considered nonvalue added time. The only time considered value added time is the time spent testing, and any time spent assembling and disassembling test fixtures is of no added value. Moreover, the current test fixture must be moved from joint to joint using a forklift due to its weight. Utilizing a forklift to manipulate the test fixture is seen as a safety hazard due to the presence 
TABLE 2: Current test fixture VSM summary.

\begin{tabular}{|c|c|c|c|c|}
\hline Process step & $\mathrm{H} / \mathrm{T}$ & $\mathrm{T} / \mathrm{T}$ & $\begin{array}{l}\text { Opportunity for } \\
\text { improvement? }\end{array}$ & Description \\
\hline Move test fixtures & $10 \mathrm{~min}$ & $0 \mathrm{~min}$ & Yes & $\begin{array}{l}\text { If test fixture can be made easier to handle and not require } \\
\text { a forklift, this time can be reduced }\end{array}$ \\
\hline Insert test plugs & $2 \mathrm{~min}$ & $0 \mathrm{~min}$ & No & $\begin{array}{l}\text { Line must be plugged; plug is simple and will be needed } \\
\text { regardless of the remaining fixture design }\end{array}$ \\
\hline Place test fixtures & $18 \min$ & $0 \mathrm{~min}$ & Yes & $\begin{array}{l}\text { If test fixture can be made simpler, this time can be } \\
\text { reduced }\end{array}$ \\
\hline Fill line & $0 \mathrm{~min}$ & $5 \mathrm{~min}$ & No & $\begin{array}{l}\text { Line must be filled for test and the test fixture does not } \\
\text { affect this step }\end{array}$ \\
\hline Perform test & $0 \min$ & $15 \mathrm{~min}$ & No & $\begin{array}{l}\text { Pressure test must be run for set amount of time per } \\
\text { requirements }\end{array}$ \\
\hline $\begin{array}{l}\text { Unthread and remove } \\
\text { fixtures }\end{array}$ & $29 \mathrm{~min}$ & $0 \mathrm{~min}$ & Yes & $\begin{array}{c}\text { If test fixture can be made simpler, this time can be } \\
\text { reduced }\end{array}$ \\
\hline Remove plugs & $1 \mathrm{~min}$ & $0 \mathrm{~min}$ & No & Plug is already simple and time is already very short \\
\hline
\end{tabular}

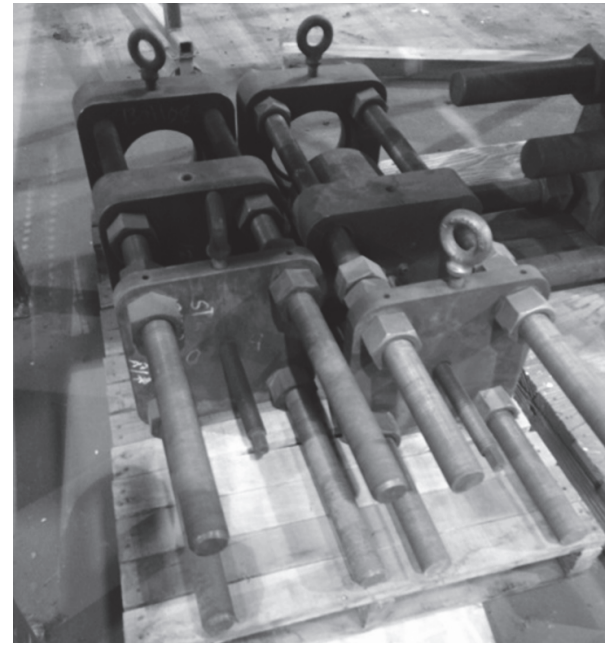

Figure 2: Current test fixture.

of large machinery around test personnel and the possibility of mishandling, which could lead to injury. The objectives of this research can then be defined as follows:

(1) Reduce Time to Test. Reduce the assembly and disassembly time of the test fixture in order to reduce the nonvalue added time for the test process.

(2) Reduce Overall Test Cost. Reduce the cost to test each line.

(3) Reduce Weight/Improve Handling. Reduce the size and weight of the test fixture such that it can be manipulated by hand (without machinery).

3.2. Measure. A current test fixture is shown in Figure 2. This current test fixture was designed to accommodate these varying sizes of the lines to be tested. Each of these lines has a different pressure rating from 5,000 psi to 20,000 psi. By attempting to accommodate these varying line sizes with a single fixture, the fixture must be made large enough to fit the largest line size and strong enough to withstand the testing of the highest pressure line. When utilized for testing it must be handled as a complete unit and weighs approximately $1,500 \mathrm{lbs}$. This large weight requires machinery such as forklifts to manipulate.

The current test fixture is comprised of a number of flat plates connected with large threaded rods. These threaded rods serve as support for the test plates to handle the tensile loads generated during testing when the fixture is under pressure. The plates and rods are made large enough to handle the highest pressure line, and the rods are long enough to allow the plates to be manipulated around varying line sizes. Value Stream Mapping (VSM) is a Lean Six Sigma tool used to analyze the current state and evaluate a future state for the series of process steps that take a product or service from its beginning to its end. For this project a VSM can be created and used to identify areas where the improvement can be made in the process and identify value and nonvalue added activities as shown in Figure 3. In this VSM, the time spent handling and testing during each step is identified and labeled as H/T (handling time) and T/T (Test Time). Each process step was reviewed to determine if an opportunity for improvement existed with relation to the test fixture design. Table 2 shows the process steps from this value stream map.

3.3. Analyze. Process Cycle Efficiency (PCE) is a Six Sigma metric that can be used to prioritize and evaluate process improvements. This metric compares value added process time to total lead or process time. From the customer's viewpoint, value added time is steps in the process that add form, function, and value to the end product or process. Nonvalue added time is steps that do not add form, function, or value to the end product or process. Process cycle efficiency is calculated as

$$
\text { PCE }=\frac{\text { VALUE ADDED TIME }}{\text { TOTAL PROCESS TIME }} \times 100 \% .
$$

Based on the VSM above, this test fixture takes an average of 30 minutes handling time to prepare for the test. The pressure test then takes 20 minutes to perform (testing time). The apparatus then takes another 30 minutes to disassemble 


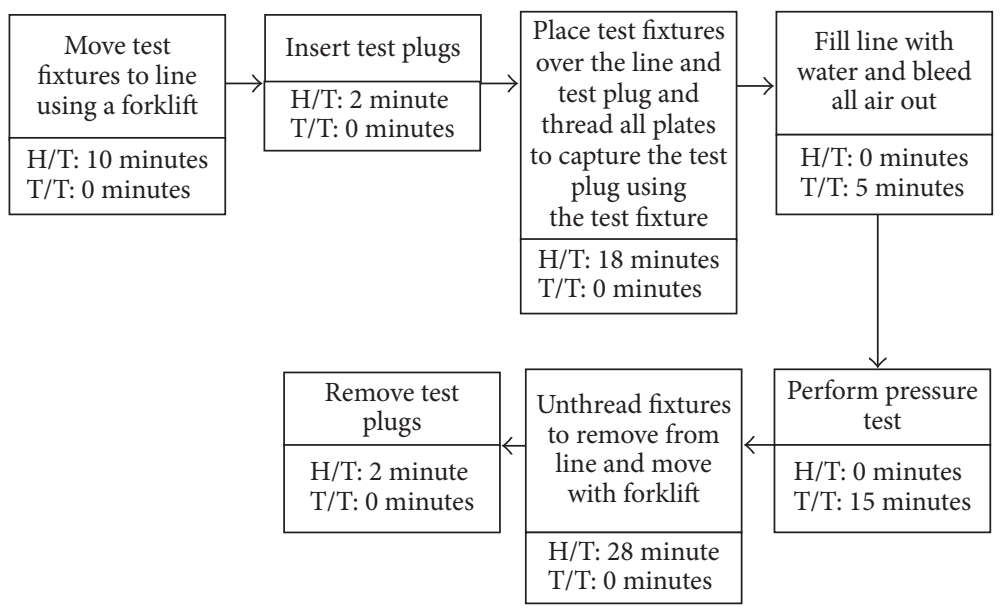

FIgURE 3: Value stream map for test using current fixture.

TABle 3: Current fixture design features.

\begin{tabular}{|c|c|c|c|}
\hline Design feature & Advantages & Disadvantages & Opportunity for improvement \\
\hline $\begin{array}{l}\text { Multipurpose: can accommodate } \\
\text { multiple line size and pressures }\end{array}$ & $\begin{array}{l}\text { Only one fixture design needed } \\
\text { for all the lines to be tested }\end{array}$ & $\begin{array}{l}\text { By necessity fixture must be very } \\
\text { large }\end{array}$ & $\begin{array}{l}\text { If multiple fixtures are allowed } \\
\text { for each line, fixtures can be } \\
\text { made smaller and simpler } \\
\text { targeted for each line }\end{array}$ \\
\hline $\begin{array}{l}\text { Self-contained: axial forces } \\
\text { generated by pressure resisted } \\
\text { completely by the test fixture }\end{array}$ & No functional advantage & $\begin{array}{c}\text { Fixture must be designed large } \\
\text { enough to handle all loads } \\
\text { generated during testing }\end{array}$ & $\begin{array}{l}\text { If some of the testing loads can } \\
\text { be shared between the test fixture } \\
\text { and line being tested, fixture may } \\
\text { be able to be reduced in size }\end{array}$ \\
\hline $\begin{array}{l}\text { Integral: test fixture assembled as } \\
\text { a complete unit }\end{array}$ & $\begin{array}{l}\text { Allowing transportation of } \\
\text { completed assembly and } \\
\text { minimizing disassembly of } \\
\text { complete fixture between tests }\end{array}$ & $\begin{array}{l}\text { Complete assembly is very heavy } \\
\text { and large requiring machinery } \\
\text { for manipulation }\end{array}$ & $\begin{array}{l}\text { If the new test fixture can be } \\
\text { created as a modular design of } \\
\text { smaller pieces, each piece could } \\
\text { be manipulated by hand } \\
\text { eliminating handling by } \\
\text { machinery }\end{array}$ \\
\hline
\end{tabular}

(total handling time for both ends). This results in a total process time of 80 minutes, 60 minutes of which is taken up by assembly and disassembly of the test fixture (handling time) and 20 minutes of which is actual testing time.

Assembly and disassembly (handling time) of the test fixture are viewed as nonvalue added time. If assembly time was reduced to zero, this would not reduce the value of the process. So for our process the PCE can be calculated as

$$
\mathrm{PCE}=\frac{20 \text { Minutes testing time }}{80 \text { Minutes total time }} \times 100 \%=25 \% .
$$

This indicates that only $25 \%$ of the time spent on testing is actually value added time. One of the main goals of the project will be to improve this value. Since there were several steps in the process where opportunities for improvement were observed, this value can be improved.

Another concern with the original test fixture was test cost. The main driver in test cost is operator cost. The current process requires two test operators each with a cost of $\$ 65$ per hour. The cost for each test using the current test fixture is therefore $\$ 173.33$. Considering that there are often hundreds of these joints that may be tested, reducing this per joint cost can result in a large saving. To evaluate the current fixture design and determine where opportunities for improvement exist, key design features of the current fixture were identified and each evaluated for possible improvement in Table 3.

Based upon the analysis of the current fixture performance using the VSM and evaluation of the design features of the current fixture, it was determined that a modular design would be utilized with a target of keeping each individual piece small enough to be handled without machinery. It was decided that each part should be limited to $50 \mathrm{lbs}$. maximum to allow individuals to handle them without the assistance of a forklift. In order to facilitate this, it was also decided to forgo the multipurpose feature of the original test fixture and to design a test fixture specifically dedicated to each line size. Design alternatives were explored that utilized the pipe to be tested to handle some of the test loads reducing the size requirement on the test fixture.

In order to evaluate the feasibility of this new approach, the hydraulic line was chosen for the initial test fixture design. This line was chosen as it is the smallest line and had the lowest pressure rating requirement (5,000 psi). Mismatch between the size of the current fixture and the requirements of this smaller line was seen as the largest and therefore targeted for the initial replacement fixture design. If the 


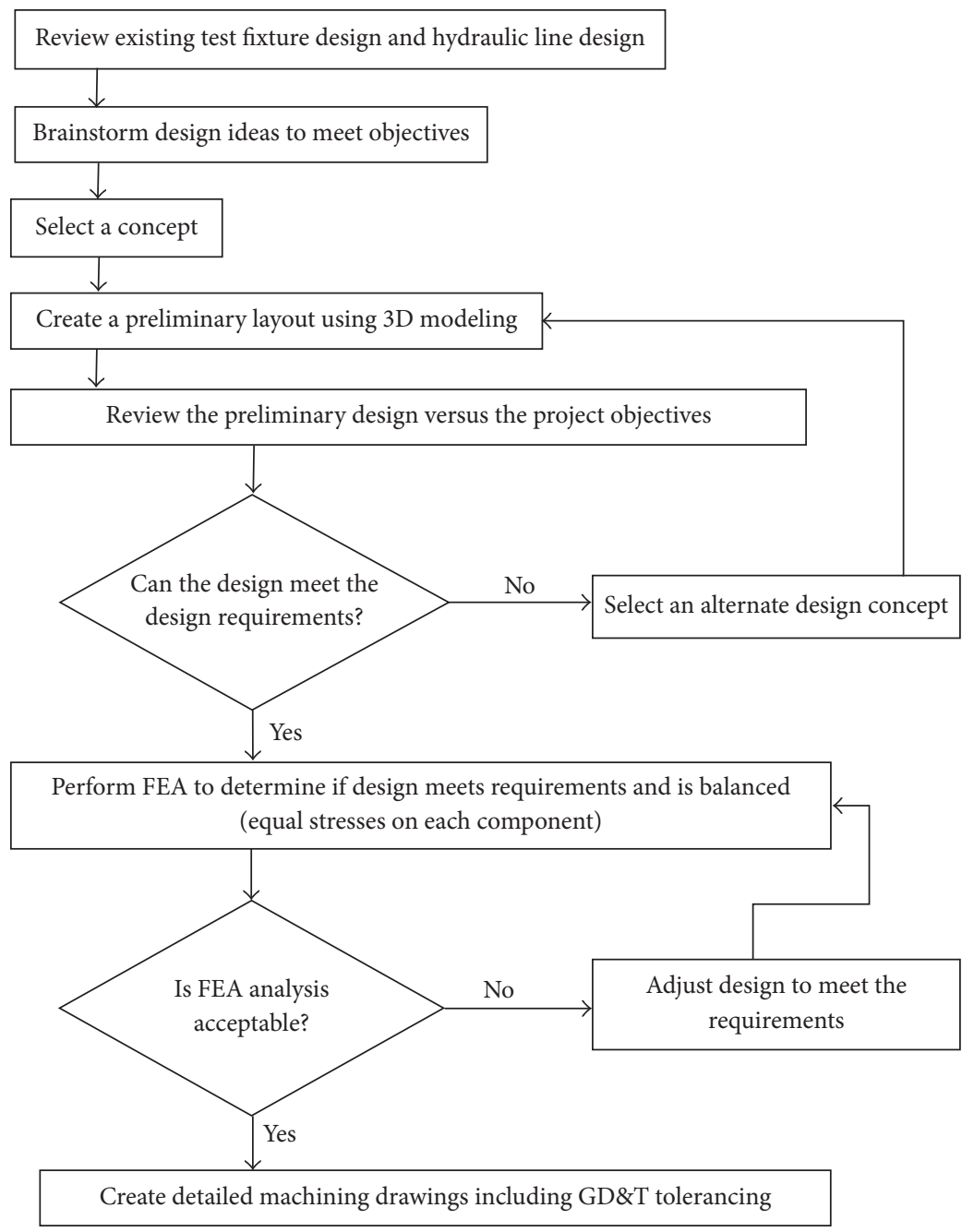

FIGURE 4: Design process flow map.

replacement fixture proved beneficial, additional fixtures for the remaining lines would be designed utilizing the same design goals and techniques.

3.4. Design. A flow map was created defining the key steps to guide the design process as shown in Figure 4. This process flow map can be applied to any new design as it is or with modification to customize it to the particular application. The Lean design tool Inventor 3D modeling software was utilized to develop the replacement test fixture design. The use of 3D modeling allowed visualization of the design before manufacturing as well as evaluation of component weight during the design process. It also facilitated productive design reviews during the development process.

Figure 5 shows the final test fixture. In this design, the marine riser hydraulic line being tested is shown. It was noted during the design process that this line featured a shoulder on the outside. It was suggested that if this shoulder was large enough it could be utilized as a support for the test fixture. If the test fixture could be designed to utilize this shoulder to transfer the axial loads generated due to pressure during the test, the fixture could be made smaller. The final fixture

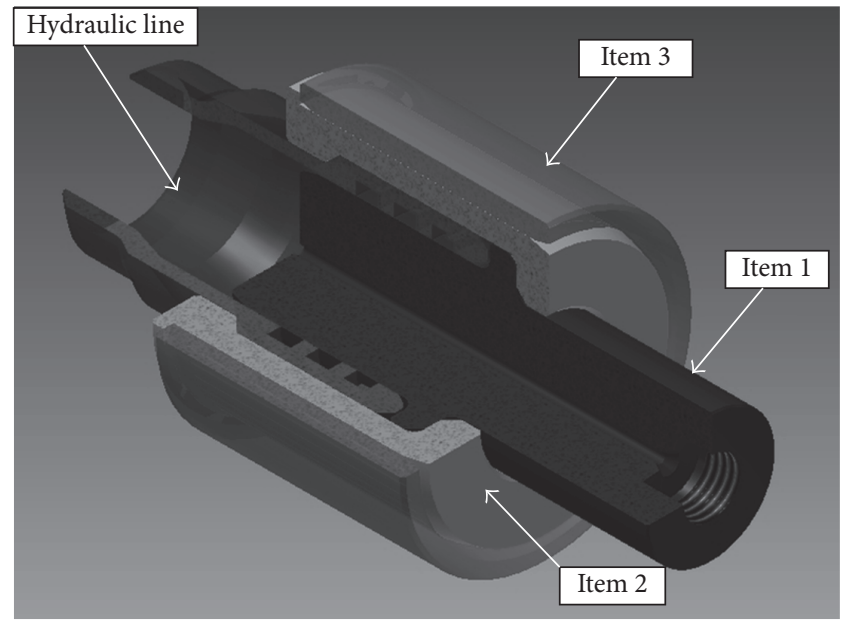

FIGURE 5: Cutaway view of final test fixture.

utilizing this shoulder comprised three main components: (1) a plug used to block the end of the hydraulic line; (2) a split housing which could be put in place capturing the plug and 
TABLE 4: Final fixture weights and stress levels.

\begin{tabular}{lcc}
\hline Component & Weight & Approximate membrane stress (Von Mises) \\
\hline Item 1, plug & $12 \mathrm{lbs}$. & $16,500 \mathrm{psi}$ \\
Item 2, split housing & $10 \mathrm{lbs}$. & $16,300 \mathrm{psi}$ \\
Item 3, sleeve & $7 \mathrm{lbs}$. & $17,600 \mathrm{psi}$ \\
\hline
\end{tabular}

TABLE 5: Fixture comparison.

\begin{tabular}{lccccc}
\hline $\begin{array}{l}\text { Fixture } \\
\text { type }\end{array}$ & $\begin{array}{c}\text { Installing fixtures } \\
\text { on each end }\end{array}$ & $\begin{array}{c}\text { Performing } \\
\text { pressure test }\end{array}$ & $\begin{array}{c}\text { Disassembling } \\
\text { fixtures from each } \\
\text { end }\end{array}$ & PCE & Test cost \\
\hline $\begin{array}{l}\text { Original test } \\
\text { fixture }\end{array}$ & 30 minutes & 20 minutes & 30 minutes & $25 \%$ & $\$ 173.33$ \\
New test fixture & 10 minutes & 20 minutes & 10 minutes & $50 \%$ & $\$ 86.67$ \\
\hline
\end{tabular}

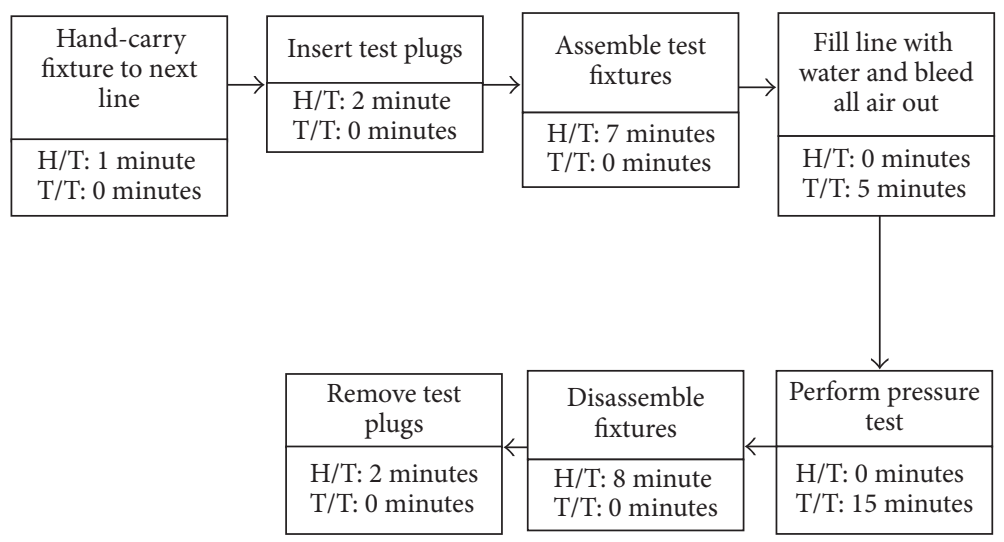

Figure 6: VSM for new test fixture.

the hydraulic line shoulder; (3) a sleeve was placed which contained and captured the split.

ANSYS Finite Element Analysis (FEA) was used to simulate the working conditions seen by the test fixture. The operating pressure of 5,000 psi was applied virtually using ANSYS, and the stresses were evaluated in the test fixture. The design was adjusted after each FEA in order to balance the stresses across the parts. Using FEA simulation allowed each part of the test fixture to be designed to carry a balanced portion of the load. In doing this, the weight of each part could be minimized to achieve the project objective.

Simulation also allowed the test fixture to be evaluated to ensure it met the design pressure requirements. The loading on the test fixture was complicated and traditional hand calculations were inadequate to fully model the stresses. FEA allowed evaluation of this complex geometry and optimization of the design in a rapid manner.

Each piece was optimized using FEA to minimize the weight while maintaining acceptable stress levels. Table 4 shows the final weight of each component of the new fixture along with the membrane stress calculated using FEA. As seen in Table 4, all components of the fixture weigh less than $12 \mathrm{lbs}$. and the stresses are well balanced across the components. Balancing the stresses using FEA allowed the design of the fixture to be optimized for weight by ensuring that parts were made as thin and light as possible while maintaining consistently acceptable stress levels.
Once the design layout and calculations were completed, machining drawings were created. A detailed tolerance accumulation study was performed and GD\&T applied to the drawings. GD\&T allows the design intent of the engineer to be clearly conveyed to the manufacturer.

3.5. Verify. In order to evaluate if the new fixture met the design goals of reducing test time and increasing test efficiency, the final test fixture was used for a job and the assembly, test, and disassembly times recorded. A VSM was created based on this new design (see Figure 6).

The nonvalue added time for fixture installation and disassembly was reduced from a total of 60 minutes to a total of 20 minutes. Since process cycle efficiency is defined as the value added time divided by the total process time, this resulted in a process cycle efficiency of $50 \%$.

$$
\mathrm{PCE}=\frac{20 \text { Minutes }(\text { testing time })}{40 \text { Minutes }(\text { total time })} \times 100 \%=50 \% \text {. }
$$

This is a significant increase from the original test fixture PCE of 25\%. This increase in PCE led to a significant cost saving for each test. The previous fixture contributed to total test personnel cost of $\$ 173.33$. The new fixture reduced that cost to $\$ 86.67$. This represents a $50 \%$ reduction in per test personnel time cost. Table 5 shows a comparison between the old fixture and the new fixture. 
Another design goal was to reduce the overall handling weight of the test fixture. By applying the DFSS approach, DFMA, and efficient design tools, as well as focusing on the design requirements, the fixture was able to be greatly reduced in size and weight. Each individual component weighs a maximum of $12 \mathrm{lbs}$. allowing the fixture to be easily assembled by one person with the assistance of machinery. This design met the project goal of improved handling and can be handled without the use of machinery.

Based upon the results of this initial design, it was decided that the advantages offered by the new design (modularity, reduced weight, and increased safety) outweighed the main advantage of the previous fixture (ability to handle multiple line sizes with one fixture). Projects were initiated to design similar new fixtures for the additional marine riser outer pipes.

\section{Conclusions}

This research shows the use of DFSS methodology along with appropriate Lean Six Sigma design tools to improve the design of a test fixture. The improved fixture increased the process cycle efficiency of the test from $25 \%$ to $50 \%$. It also reduced the cost of running the test by $50 \%$. At the same time handling was improved allowing a safer and more user friendly test process. The design process flow map created can be utilized for any design project as is or can be modified as needed for specific design tasks. The Lean tools such as value stream mapping and Lean design tools such as 3D modeling, Finite Element Analysis, GD\&T dimensioning, and DFMA can be applied for any design project to improve the quality of the finished design.

The oilfield industry in general has been slow to apply Six Sigma techniques to the design of equipment. This industry is notorious for falling victim to the common roadblocks by implementing unique solutions to design problems. Once a design is established as traditional, comments like "that's not how we do things" and "we've always done it this way" often impede the implementation of innovative solutions. Though specifically about the design of a marine riser hydraulic line test fixture, this research shows how using the DFSS methodology and Lean design tools can help break those chains and assist with developing novel solutions to design problems that reduce nonvalue added time by increasing the efficiency of quality control and testing operations while also increasing safety.

\section{Competing Interests}

The authors declare that they have no competing interests.

\section{Acknowledgments}

This research is partially supported by Louisiana Department of Natural Resources (DNR) under Contract no. 2031-14-03.

\section{References}

[1] J. P. Womack, D. T. Jones, and D. Roos, The Machine That Changed the World, Free Press, New York, NY, USA, 2007.

[2] T. R. Browning, "Value-based product development: refocusing lean," in Proceedings of the IEEE Engineering Management Society, IEEE, Albuquerque, NM, USA, 2000.

[3] D. Näslund, "Lean, six sigma and lean sigma: fads or real process improvement methods?" Business Process Management Journal, vol. 14, no. 3, pp. 269-287, 2008.

[4] M. P. J. Pepper and T. A. Spedding, "The evolution of lean six sigma," International Journal of Quality and Reliability Management, vol. 27, no. 2, pp. 138-155, 2010.

[5] A. Haggerty, D. Lewis, H. McManus, E. Murman, and A. Weigel, Lean Engineering Basics V7.6, MIT OpenCourseWare, 2012.

[6] J.-C. Kihn, "Brining lean thinking to R\&D," Research-Technology Management, vol. 55, no. 5, p. 68, 2012.

[7] M. N. Kennedy, Product Development for the Lean Enterprise, The Oaklea Press, 2008.

[8] R. Schmidt and T. Schipper, "Lean methods for creative development," AME Target Magazine, vol. 22, no. 4, pp. 14-27, 2006.

[9] N. Chugani, V. Kumar, J. A. Garza-Reyes, L. Rocha-Lona, and A. Upadhyay, "Investigating the green impact of Lean, Six Sigma, and Lean Six Sigma: a systematic literature review," International Journal of Lean Six Sigma, In press.

[10] H. McManus, A. Haggerty, and E. Murman, "Lean engineering: doing the right thing right," in Proceedings of the 1st International Conference on Innovation and Integration in Aerospace Sciences, Queen's University Belfast, 2005.

[11] M. B. Mehta, "Promoting awareness in manufacturing students of key concepts of lean design to improve manufacturing quality," in Proceedings of the 119th ASEE Annual Conference and Exposition, San Antonio, Tex, USA, June 2012.

[12] P. Johnston, The Role of Computer Aided Engineering in Developing a Combined Trash and Recycling Truck: A Case Study, All Theses, Paper 279, http://tigerprints.clemson.edu/ all_theses/279.

[13] S. E. Mason, C. R. Nicolay, and A. Darzi, "The use of Lean and Six Sigma methodologies in surgery: a systematic review," The Surgeon, vol. 13, no. 2, pp. 91-100, 2015.

[14] A. Douglas, J. Douglas, and J. Ochieng, "Lean Six Sigma implementation in East Africa: Findings From A Pilot Study," TQM Journal, vol. 27, no. 6, pp. 772-780, 2015.

[15] A. Mishra, Six sigma based fixture design and process improvement [M.S. thesis], University of Louisiana at Lafayette, 2013. 


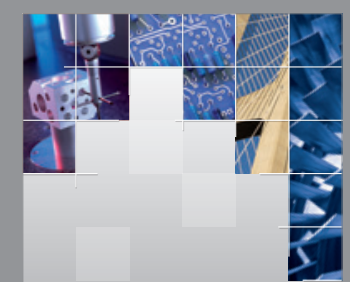

\section{Enfincering}
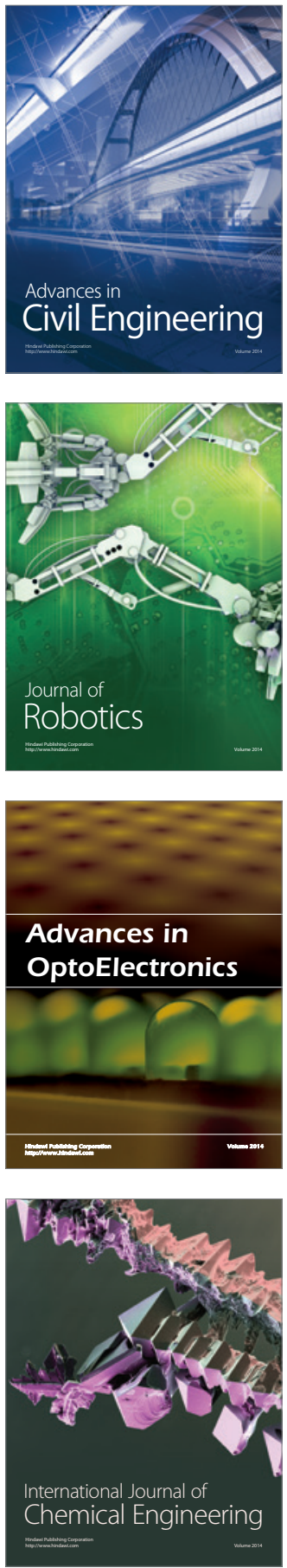

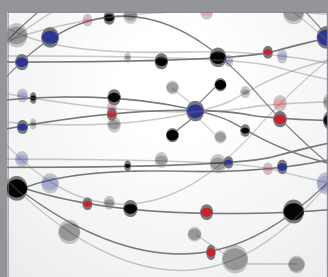

The Scientific World Journal

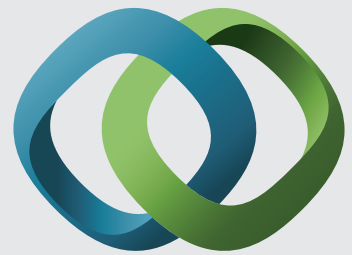

\section{Hindawi}

Submit your manuscripts at

http://www.hindawi.com
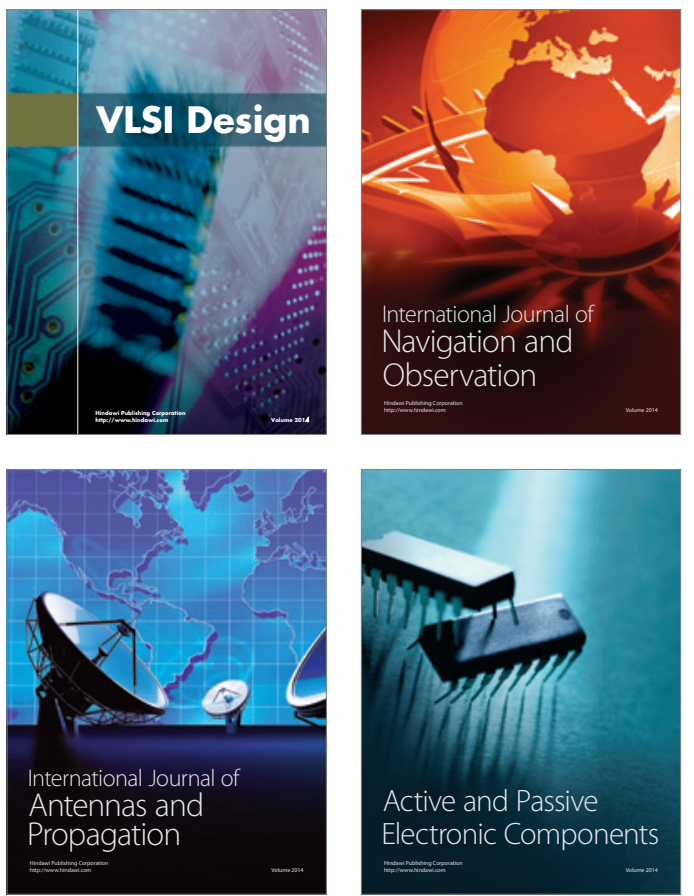
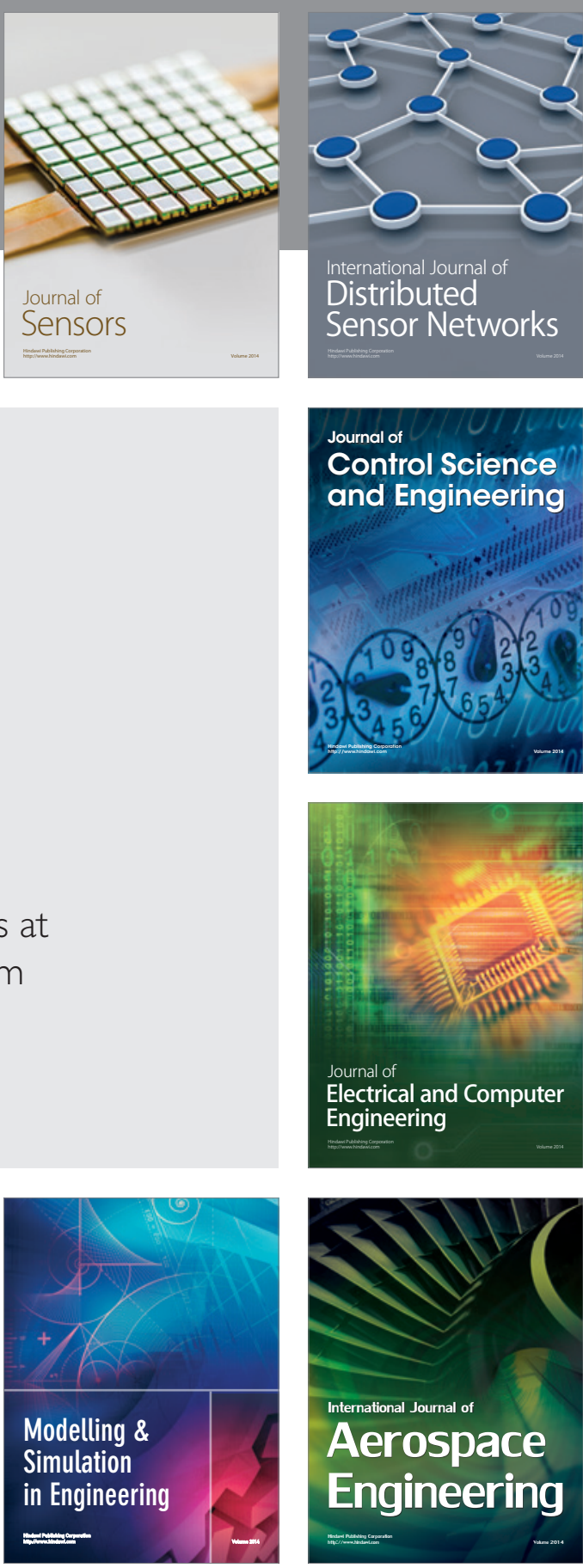

International Journal of

Distributed

Sensor Networks

Journal of

Control Science

and Engineering
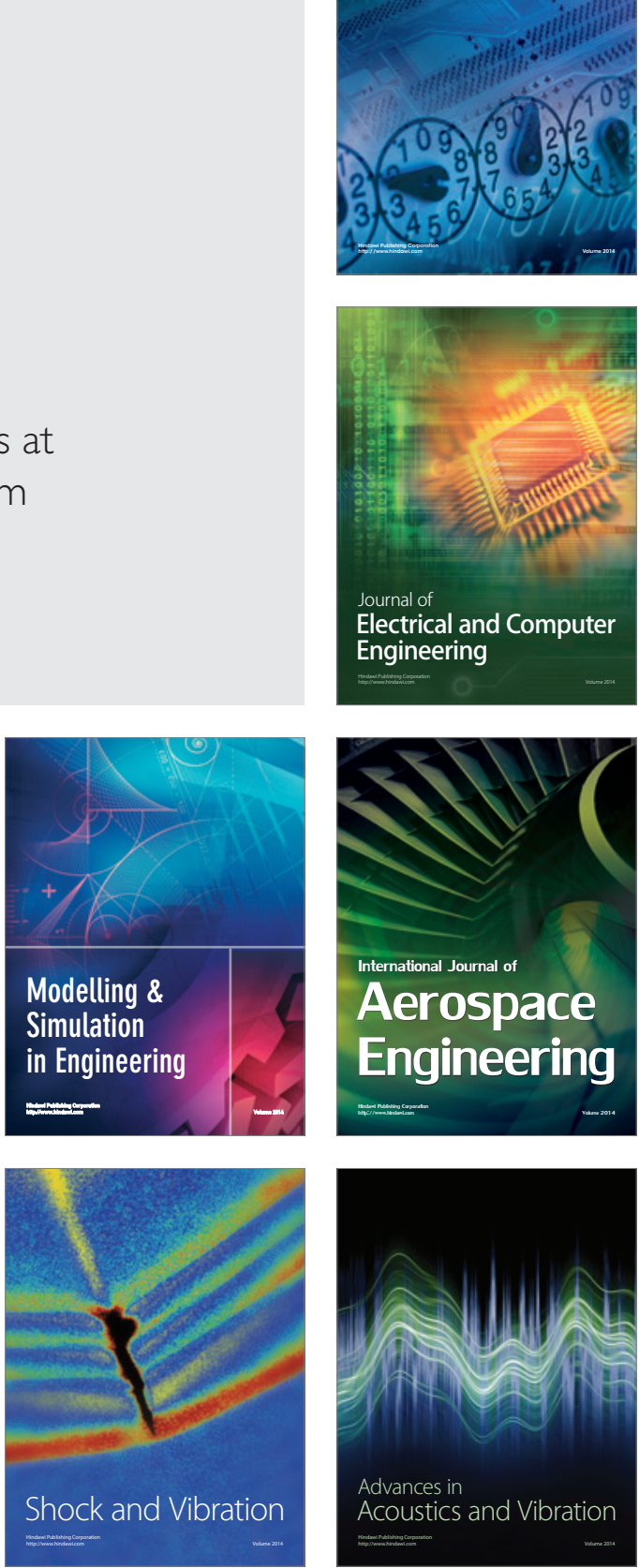